\title{
Flipping the Classroom: Effects on Course Experience, Academic Motivation, and Performance in an Undergraduate Exercise Science Research Methods Course
}

\author{
Jody Langdon \\ Georgia Southern University \\ jlangdon@georgiasouthern.edu \\ Diana Sturges \\ Georgia Southern University
}

\begin{abstract}
The goal of the study was to determine the effects of the Flipped Classroom Model (FCM) on students' course experience, basic need satisfaction, motivation, and academic performance in an undergraduate Research Methods course for exercise science majors. One section received instruction in a Traditional Lecture Model (TLM), while the other section received instruction via the FCM. An adapted survey was administered to approximately 175 students, with $83 \%$ responding. Significant differences were seen in course experience (learning resources and course organization). Analysis of lecture viewing data revealed that students in the FCM did not adhere to a level of lecture viewing that would ensure success in the course. The FCM was determined to be a viable alternative to TLM, as motivation and general course experiences was high for both formats, however instructors must be aware of the need to reinforce preparation for in-class work.
\end{abstract}

Key Words: Academic motivation, course experience, flipped classroom, kinesiology, research methods, undergraduate

\section{Introduction}

Higher education in general and higher education in kinesiology is profoundly affected by the current age of supercomplexity (Barnett, 2004). Among the characteristics of supercomplexity such as globalization, interpretation of higher education with the wider host society, marketization of higher education and competition, an important place is occupied by the revolution brought by the arrival of digital technologies (Barnett, 2004). They change the way in which information and knowledge is generated and shared. In a discussion of supercomplexity as it relates to kinesiology, Block and Estes (2011) state, "kinesiology scholars looked at the big picture and concluded technology and the discipline of kinesiology is not an easy fit." However, digital technologies are used increasingly to offer classes at all universities. A relatively recent trend in higher education is the flipped classroom model (also known as the inverted classroom), which relies heavily on technology use. The Flipped Classroom Model (FCM) challenges the idea of the traditional lecture model (TLM). In TLM, students attend class to get first exposure to material through lecture, and then try to make sense of it through activities after class, while in the FLM the first exposure is shifted to outside of class and time in 
class is utilized to work through problems, advance concepts, and engage in collaborative learning (Tucker, 2012).

There are multiple definitions for the flipped classroom ranging from Lage, Platt, and Treglia's (2000) "events that traditionally taken place inside the classroom now take place outside and vice versa" to "an educational technique that consists of two-parts: interactive group learning activities inside the classroom, and direct computer-based individual instruction outside the classroom (Bishop \& Verleger, 2013)". Bishop (2013) and Strayer (2012) insist that to qualify as a flipped classroom, systematic use of technology in the course is necessary. Although recent literature differentiates between a flipped classroom and flipped learning (Chen, Wang, \& Chen, 2014), for the purpose of this manuscript, a flipped classroom is defined as "using time outside of class to read and view online lectures, while class time can be spent on hands-on learning, group discussion, and question/answers sessions" (Gerstein, 2012). Providing students with active learning opportunities shifts the teacher-centered approach to a student-centered environment and further engages students in the learning process (Machemer \& Crawford, 2007). In a study of student perceptions, Lumpkin, et al. (2015) found that undergraduate students believe that in-class activities such as small groups and pairs, checks for understanding/review questions, exploratory writing assignments and mobile polling tools positively impacted their learning along with out-of-class activities such as mini lectures, power point slides and videos.

There is no scripted method to flipping the classroom and the instructors can choose to do a full flip that involves the entire course content or a partial flip that only involves certain units or lessons (Bergmann \& Sams, 2012). Although the empirical research is fairly new, the amount of research on FCM is growing in both undergraduate classroom applications (Davies, Dean, \& Ball, 2013; Strayer, 2012; Westermann, 2014; Wilson, 2013), as well as graduate level or professional courses (Lemmer, 2013; Miller, McNear, \& Metz, 2013; Tune, Sturek, \& Basile, 2013).

The existing research argues that flipped classrooms are more efficient (Baepler, Walker, \& Driessen, 2014), take less time, and eliminate the need for the teacher to repeat content (Brunsell \& Horejsi, 2013). There is some evidence that contact time can be reduced by twothirds while achieving similar or slightly better outcomes (Baepler et al., 2014). Furthermore, flipped classrooms were reported to improve student-teacher interaction (Goodwin \& Miller, 2013), allow for more student-to-student collaboration to solve and resolve problems individually and as a group (Brunsell \& Horejsi, 2013; Lujan \& DiCarlo, 2014) and provide students with the ability to self-pace through the subject material (Davies et al., 2013; Lujan \& DiCarlo, 2014).

The effects of FCM on academic performance in class were evaluated in courses such as nursing (Missildine, Fountain, Summers, \& Gosselin, 2013), statistics (Wilson, 2013), humancomputer interaction (Day \& Foley, 2006), biology (Morravec, Williams, Aguilar-Roca, \& O’Dowd, 2010), chemistry (Fitzgerald \& Li, 2015) and basic pharmaceutics (McLaughlin, Roth, Glatt, Gharkholonarehu, Davidson, Griffin, \& Mumper, 2014). When compared to a traditional lecture format, the FCM in these studies showed an increase in student academic performance on exams and/or assignments (Chen, Wang, \& Chen, 2014; Tune et al., 2013). However, other studies did not find a significant difference in final grades between a FCM and a TLM (Lage et al., 2000; Johnson \& Renner, 2012; Strayer, 2012; Davies et al., 2013).

Student perceptions have also yielded inconsistent results. Lage et al. (2000) identified that most students have a positive perception of the flipped model, although some students 
invariably disliked it and perceived the increased expectations for personal responsibility in learning as unfair or unreasonable (Wilson, 2013). Students reported experiencing more innovation and cooperation in a flipped classroom but were less satisfied with their preparation (Strayer, 2012), the web-based instruction (Frederickson, Reed, \& Clifford, 2005), and required more support and facilitation from the instructor (Kim, Kim, Khera, \& Getman, 2014). The FCM had a positive impact on students' attitudes toward a class (Wilson, 2013), improved perceptions of the learning environment (Baepler et al., 2014) and the perception that the flipped classroom greatly enhanced their learning (McLaughlin et al., 2014; Zappe, Leicht, Messner, Litzinger, \& Lee, 2009). Students also reported a more student-centered approach (Kim et al., 2014) and increased engagement (Goodwin \& Miller, 2013) in the flipped model. Davies (2013) showed no differences between flipped and traditional models in terms of student assessment of the value of class, how much was learned in class, willingness to recommend the class to others, or student evaluations of activities, although the mean scores/grades were more favorable in the flipped class.

As a way to examine student experiences with the FCM, self-determination theory (Ryan $\&$ Deci, 2000) was used as a theoretical framework for the current study. Investigating student motivation through a continuum provides researchers with a stronger evaluation of the student experience with new learning models. Many theories view motivation as a unitary concept-one that differs in amount rather than type. In contrast, self-determination theory (SDT) considers motivation to exist along an underlying continuum of autonomy: from amotivation at one end of the spectrum to intrinsic motivation at the other end (Ryan \& Deci, 2000). With amotivation, the person experiences absence of intention or motivation, with passivity and an absence of autonomy. With extrinsic motivation, the person engages in an activity because it leads to a separable outcome or consequence, such as obtaining a reward or avoiding a punishment. There are three subscales of extrinsic motivation: external regulation, in which the person is motivated by the salience of external rewards or punishments; introjected regulation, in which the person is motivated by the salience of internal rewards (e.g., pride) or punishments (e.g., guilt) and identified regulation, in which the person is motived by the value and/or importance of the activity. With intrinsic motivation, the person engages in an activity because it is inherently satisfying and enjoyable. Vallerand et al. (1992) included three separate subscales of intrinsic motivation: intrinsic motivation to know (when an individual engages in a behavior for the satisfaction experienced while learning or trying to understand something new), intrinsic motivation to accomplish (when an individual engages in a behavior for the pleasure experienced while trying to accomplish a task or create something), and intrinsic motivation to experience stimulation (when an individual engages in a behavior in order to experience stimulating or exciting sensations).

Several studies have used the SDT framework to examine student academic motivation using the Academic Motivation Scale (AMS; Vallerand et al., 1992). AMS was adapted for use in specific courses such as nutrition, physics, and human anatomy and physiology (Maurer, Allen, Gatch, Shankar, \& Sturges, 2012; Maurer, Allen, Gatch, Shankar, \& Sturges, 2013). In these three disciplines, both intrinsic motivation and extrinsic motivation were rated as higher than amotivation, and extrinsic motivation was rated as higher than intrinsic motivation, although some differences between majors were also observed.

Many studies on the FCM used a single group design (Bergmann \& Sams, 2012; Lage et al., 2000; Zappe et al., 2009). Studies that had a control group (Moravec et al., 2010; Strayer, 2012) did not follow students' performance over the entire semester. Few studies in this area 
consider students' academic motivation in the course. In addition, little to no data concerning the adherence to the flipped model have been investigated. To fill this gap, the purpose of this study was to compare the flipped and traditional classroom formats in an undergraduate research methods class. The following research questions were considered:

1. Are there differences in students' perceptions of course experience between a FCM and TLM?

2. Are there differences in students' academic motivation between a FCM and TLM?

3. Are there differences in students' academic performance between FCM and TLM as measured by final grades?

4. What is the effect of lecture watching compliance on students' academic performance in the FCM?

\section{Methods}

\section{Participants}

Participants in this study included 175 undergraduate exercise science students from a southeastern university. Overall, $62.5 \%$ of students had above a 3.0 GPA. Within both groups, a majority of students reported spending 1-3 hours a week studying for the course (FCM $=46.8 \%$; TLM $=36.8 \%$ ). With regards to attendance in class and study habits of participants, a greater percentage of students in the FCM attended all class sessions. These students also devoted more time to studying outside of class. A breakdown of demographic/other questions is located in Table 1. 
Langdon and Sturges

Table 1. Demographic/other Information by Class Format*

\begin{tabular}{|c|c|c|}
\hline & $\begin{array}{l}\text { Flipped } \\
\mathrm{N}=49\end{array}$ & $\begin{array}{l}\text { Traditional } \\
\mathrm{N}=196\end{array}$ \\
\hline \multicolumn{3}{|l|}{ Gender } \\
\hline Female & $65 \%$ & $74 \%$ \\
\hline Male & $35 \%$ & $26 \%$ \\
\hline \multicolumn{3}{|l|}{ Race/Ethnicity } \\
\hline White & $60 \%$ & $84 \%$ \\
\hline Black & $31 \%$ & $16 \%$ \\
\hline Hispanic & $3 \%$ & -- \\
\hline Asian & $2 \%$ & -- \\
\hline Other & $5 \%$ & -- \\
\hline \multicolumn{3}{|l|}{ Class standing } \\
\hline Sophomores & $12 \%$ & $6 \%$ \\
\hline Juniors & $73 \%$ & $46 \%$ \\
\hline Seniors & $16 \%$ & $48 \%$ \\
\hline Other & $1 \%$ & -- \\
\hline Self- Reported GPA & $\mathrm{M}=3.39, \mathrm{SD}=1.04$ & $\mathrm{M}=3.03, \mathrm{SD}=1.10$ \\
\hline $\begin{array}{l}\text { How Often Do You Attend } \\
\text { Class? }\end{array}$ & $53.2 \%$ every time & $33.7 \%$ every time \\
\hline $\begin{array}{l}\text { How often do you do } \\
\text { worksheets/readings for this class } \\
\text { before the period they are due? }\end{array}$ & $\begin{array}{l}17 \% \text { every time } \\
6.4 \% \text { almost every time } \\
36.2 \% \text { most times } \\
36.2 \% \text { sometimes } \\
4.3 \% \text { hardly ever }\end{array}$ & $\begin{array}{l}10.5 \% \text { every time } \\
10.5 \% \text { almost every time } \\
26.3 \% \text { most times } \\
34.7 \% \text { sometimes } \\
17.9 \% \text { hardly ever }\end{array}$ \\
\hline \multicolumn{3}{|l|}{$\begin{array}{l}\text { How would you describe your } \\
\text { studying patterns? }\end{array}$} \\
\hline Erratic or Random & $11.1 \%$ & $19.1 \%$ \\
\hline Crammed right before the test & $33.3 \%$ & $29.8 \%$ \\
\hline $\begin{array}{l}\text { Spread out studying between tests } \\
\text { with an increase right before the } \\
\text { test }\end{array}$ & $51.9 \%$ & $51.1 \%$ \\
\hline Evenly spread out between tests & $3.7 \%$ & -- \\
\hline
\end{tabular}

*Note: Demographic data was collected at the end of the semester.

\section{Procedures}

Research Methods in Kinesiology is a 3-credit class required of all students with a major in exercise science or athletic training. After obtaining IRB approval, the study targeted all students enrolled in two sections of the research methods course in the Spring and Fall 2014 semesters, all taught by the same instructor. It is important to note that students were already enrolled in certain sections prior to the onset of the study and the instructor had no control over this selection. One 
section each semester was offered in a traditional lecture format (TLM) and served as a control group, while the other section was taught using the Flipped Classroom Model (FCM) and served as the experimental group. Both sections received the exact same information, which was organized by modules. See class content and schedule in Table 2. Students in the TLM came to class twice a week, were given lectures in class and instructed to complete assignments outside of class. Students in the FCM met only once per week and were given recorded lectures online. Unlike in the TLM, the online lectures were no more than 10 minutes each. To present the same amount of material, each module contained several lectures. Class time was spent answering questions and working on the assignments developed by the instructor.

\begin{tabular}{|l|l|}
\hline \multicolumn{2}{|c|}{ Table 2. Class Content and Schedule for Both Formats } \\
\hline Module Number & Module Topic \\
\hline 1 & Introduction to Research Methods \\
\hline 2 & Reviewing Literature \\
\hline 3 & Sampling Procedures \\
\hline 4 & Measurement \\
\hline 5 & Experimental Design \\
\hline 6 & Physical Activity Epidemiology \\
\hline 7 & Understanding Statistics \\
\hline 8 & Evaluating Research \\
\hline 9 & Qualitative Research \\
\hline
\end{tabular}

At the end of the semester, students were asked to participate in a survey. Of the 175,145 completed the survey, reflecting a response rate of $83 \%$. Participation in the survey was voluntary and no incentives were offered. The survey included an "active" consent form giving the researchers permission to use survey data and course grades. Even if students did not complete the survey, a consent form was obtained to analyze academic performance and lecture viewing data. Although surveys and grades were administered and/or collected at the end of the semester, students were aware that a research study was taking place during the entire semester.

\section{Measures}

The 91-question survey included the Course Experience Questionnaire (Griffin, Coates, Mcinnis, \& James, 2003); the Basic Need Satisfaction in Relationships Scale (La Guardia, Ryan, Couchman, \& Deci, 2000); the adapted Academic Motivation Scale (Vallerand et al., 1992) and eight demographic/other questions (gender, race/ethnicity, class standing, self-reported GPA, attendance, completion of materials prior to class, study habits, hours of study).

Course Experience Questionnaire (CEQ). The 34-item CEQ (Griffin et al., 2003) was used to assess student perceptions and satisfaction with the course. The current study observed 7 out of the 11 original subscales of the CEQ: generic skills, appropriate assessment, appropriate workload, emphasis on independence, learning resources, course organization, and intellectual motivation. Participants reported their perceptions of general issues about the course on a 5-point Likert scale ranging from 1 (definitely disagree) to 5 (definitely agree). Sample items included "This course helped me to develop my problem-solving skills" (generic skills), "To do well on this course all you really need is a good memory" (appropriate assessment), "'The workload is too heavy" (appropriate workload), "Overall, I am satisfied with the quality of this course" 
(emphasis on independence), "It was made clear what resources were available to help me learn" (learning resources), "The course was well organized" (course organization), and "I found my studies intellectually stimulating" (intellectual motivation). Scoring involved taking the average of the items in each of the 7 constructs. Previous literature reported the validity and reliability of this instrument to have a Cronbach's alpha ranging from .85 - .93. Cronbach's alpha levels for the current study are located in Table 3.

Basic Need Satisfaction in Relationships Scale (BNS-RS). The 21-item BNS-RS (Le Guardia et al., 2000) was used to assess basic psychological needs of participants' relationships with their instructor. The scale measured the three basic psychological needs of participants: autonomy, competence, and relatedness. Participants reported their perceived autonomy, competence, and relatedness when they were with their instructor on a 7-point Likert scale ranging from 1 (not true at all) to 7 (very true). Sample items included "When I am with my instructor, I feel free to be who I am" (autonomy), "When I am with my instructor, I feel very capable and effective" (competence), and "When I am with my instructor, I feel a lot of closeness" (relatedness). Scoring involves taking the average of the items in each of the 3 constructs. Previous literature reported the validity and reliability of this instrument to have a Cronbach's alpha ranging from .85 - .94. Cronbach's alpha levels for the current study are located in Table 3. Due to the low reliability of autonomy and competence, only relatedness was analyzed for this study.

The adapted Academic Motivation Scale (AMS). The adapted 28-item Academic Motivation Scale (38) was used to measures students' self-determined motivation towards academic decisions on the self-determination theory continuum. AMS measures a total of 7 subscales: intrinsic motivation to know, intrinsic motivation to accomplish, intrinsic motivation to experience stimulation, identified regulation, introjected regulation, extrinsic regulation, and amotivation (Deci \& Ryan, 2000). Scoring for this scale involved averaging the total score of each construct and its subscales that are reported on a 7-point Likert scale ranging from 1 (does not correspond at all) to 7 (corresponds exactly). The original AMS scale was adapted to a discipline-specific scale (research methods) based on previously published techniques (Maurer et al., 2012, 2013). Sample items included "Because I experience pleasure and satisfaction while learning new things about research methods" (intrinsic motivation to know), "For the pleasure I experience while surpassing myself in my studies of research methods" (intrinsic motivation to accomplish), "For the intense feelings I experience when I am communicating my own ideas about research methods to others" (intrinsic motivation to experience stimulation), "Because I think that this class will help me better prepare for the career I have chosen" (identified regulation), "To prove to myself that I am capable of passing this class" (introjected regulation), "Because with only a high school degree I would not find a high-paying job later on" (external regulation), and "Honestly, I don't know; I really feel that I am wasting my time in this class" (amotivation). Cronbach's alpha levels for the current study are located in Table 3. 
Langdon and Sturges

Table 3. Reliability of Survey Subscales

\begin{tabular}{|c|c|c|}
\hline Scale & Construct & Cronbach's $\alpha$ \\
\hline Course & Generic Skills & .79 \\
\hline Experience & Appropriate Assessment & .51 \\
\hline \multirow[t]{5}{*}{ Questionnaire } & Appropriate Workload & .72 \\
\hline & Emphasis on Independence & .65 \\
\hline & Learning Resources & .69 \\
\hline & Course Organization & .72 \\
\hline & Intellectual Motivation & .87 \\
\hline \multirow{3}{*}{$\begin{array}{ll}\text { Basic } & \text { Need } \\
\text { Satisfaction } & \end{array}$} & Autonomy & $.49^{*}$ \\
\hline & Competence & $.56^{*}$ \\
\hline & Relatedness & .76 \\
\hline \multirow{7}{*}{$\begin{array}{l}\text { Academic Motivation } \\
\text { Scale }\end{array}$} & Intrinsic: To Know & .89 \\
\hline & Intrinsic: To Accomplish & .82 \\
\hline & Intrinsic: To Experience Stimulation & .90 \\
\hline & Extrinsic: Identified Regulation & .86 \\
\hline & Extrinsic: Introjected Regulation & .82 \\
\hline & Extrinsic: External Regulation & .72 \\
\hline & Amotivation & .82 \\
\hline
\end{tabular}

*Not reliable

\section{Data Analysis}

After ensuring normality of the data, reliability of the questionnaires was calculated using Cronbach's alpha. Descriptive statistics were run on all subscales, including course experience, basic need satisfaction, and academic motivation. Descriptive statistics were also run on final course grades and lecture watching (average number of views, average viewing time, and average drop-off times). Independent t-tests were run between students in the FCM and TLM to determine differences in students' perceptions and satisfaction with the course experience, basic need satisfaction, academic motivation, and final course grades. To further investigate lecturewatching compliance among participants in the FCM, data was separated into "before-midterm" and "after-midterm." A dependent t-test was then run on average number of views, average viewing time, and average drop-off times. Finally, a one-way ANOVA was run to determine the effect of lecture drop-off times on final course grades. An alpha level of .05 was adopted for all analyses.

\section{Results}

Research question 1. Are there differences in students' perceptions of course experience between a FCM and TLM?

Students typically felt satisfied with the course experience, regardless of the format of course offered. Table 4 illustrates the mean scores of both groups. Of note are the high values on learning resources and course organization areas of CEQ, which were higher in the TLM. The ttest comparing the students' perceptions of course experience revealed significant differences 
only in students' learning resources, $\mathrm{t}(144)=-3.35, \mathrm{p}=.01$, and course organization, $\mathrm{t}(144)=$ $2.91, \mathrm{p}<.01$.

Due to the low reliability of autonomy and competence on BNS-RS, only relatedness was analyzed for this study. Students generally felt that basic needs were satisfied in both course formats, with high levels of relatedness reported. No significant differences were found in relatedness between the TLM and FCM.

Table 4. Means and Standard Deviations on CEQ and BNS-RS by Format

\section{Questionnaire} Area of Evaluation

Course Experience

Questionnaire

Basic Need Satisfaction

Relationship Scale

$* * \mathrm{p}<.01$

Research Question 2. Are there differences in students' academic motivation between a FCM and TLM?

Academic motivation was moderate to high, especially among extrinsic, external, and introjected regulations, and intrinsic motivation to know (See Table 5). However, there were no significant differences between the TLM and FCM groups. There was a slight difference in the values for different types of motivation between the two groups. FCM students held external regulation highest, intrinsic motivation to know (second highest) and introjected regulation (third highest), while the TLM students reported introjected regulation highest, external regulation (second highest) and intrinsic motivation to know (third highest).

Table 5. Means and Standard Deviations on Academic Motivation Scale by Format

\begin{tabular}{lllllll}
\hline Motivational Construct & \multicolumn{2}{l}{ Flipped } & \multicolumn{3}{l}{ Ranking } & \multicolumn{2}{l}{ Traditional } & Ranking \\
\cline { 2 - 7 } & Mean & SD & & Mean & SD \\
\hline Intrinsic Motivation to Know & 4.73 & 1.35 & 2 & 4.75 & 1.44 & 3 \\
Intrinsic Motivation to Accomplish & 3.99 & 1.23 & 5 & 4.43 & 1.35 & 4 \\
Intrinsic Motivation to Experience & 3.04 & 1.41 & 6 & 2.96 & 1.49 & 7 \\
Stimulation & & & & & & \\
Extrinsic Motivation -Identified Regulation & 4.17 & 1.71 & 4 & 4.27 & 1.86 & 5 \\
Extrinsic Motivation - Introjected & 4.72 & 1.11 & 3 & 4.82 & 1.15 & 1 \\
Regulation & & & & & & \\
Extrinsic Motivation-External Regulation & 4.79 & 1.49 & 1 & 4.76 & 1.56 & 2 \\
Amotivation & 2.89 & 1.32 & 7 & 3.04 & 1.68 & 6 \\
\hline
\end{tabular}

Journal of the Scholarship of Teaching and Learning, Vol. 18, No. 4, December 2018.

josotl.indiana.edu 
Research Question 3. Are there differences in students' academic performance between a FCM and TLM as measured by final grades?

Overall grades in the course were somewhat negatively skewed, with most students earning an $80 \%$ or above. In addition, course grades were not significantly different, with the FCM participants earning an average of $87.03 \%(\mathrm{SD}=12.75)$ and the TLM participants earning an $87.49 \%(\mathrm{SD}=9.31)$.

Research Question 4. What is the effect of lecture watching compliance on students' academic performance in the FCM?

In comparing lecture viewing before and after midterm for students in the FCM group, there were significant differences in average number of plays, $\mathrm{t}(61)=6.67, \mathrm{p}<.001$ and average dropoff times, $\mathrm{t}(61)=4.21, \mathrm{p}<.001$. No significant differences were found for average viewing time. Means and standard deviations for these data are located in Table 6. After splitting the data into drop-off time categories, the one-way ANOVA revealed significant differences in final grade percentage based on these categories, $\mathrm{F}(3,59)=4.52, \mathrm{p}<.01$. More specifically, students who viewed at least $75 \%$ of the lecture or more had significantly higher grades than those who watched $25 \%$ or less on average. Means and standard deviations on these items are located in Table 7.

Table 6. Lecture viewing data by module

\begin{tabular}{|l|l|l|l|l|}
\hline Variable & \multicolumn{2}{l|}{ Before Midterm } & \multicolumn{2}{l|}{ After Midterm } \\
\hline & $\mathrm{M}$ & $\mathrm{SD}$ & $\mathrm{M}$ & $\mathrm{SD}$ \\
\hline Average Number of Plays*** & 1.36 & .45 & .75 & .80 \\
\hline Average Drop-off Times*** & 50.86 & 25.68 & 31.87 & 38.61 \\
\hline Average Viewing Time & 11.56 & 6.16 & 9.22 & 12.70 \\
\hline
\end{tabular}

$* * * p<.001$

Table 7. Comparison of Average Drop-Off Times

\begin{tabular}{|l|l|l|}
\hline Drop-Off Time Categories & \multicolumn{2}{|l|}{ Final Grade Percentage } \\
\hline & M & SD \\
\hline $0-24 \%$ & 81.18 & 12.15 \\
\hline $25-49 \%$ & 87.83 & 7.56 \\
\hline $50-74 \%$ & 88.95 & 6.45 \\
\hline $75-100 \%$ & 93.95 & 2.78 \\
\hline
\end{tabular}

\section{Discussion}

With the relative novelty of FCM, few studies have investigated student perceptions of course experience, academic motivation, and performance as compared to TLM. This study was designed specifically to directly compare these measures in a TLM with a full FCM in an undergraduate class. In this study, students had the same instructor, course materials, lectures and assignments, including final exams.

In the current study, the only significant differences seen in course experience were within learning resources and course organization areas. For the learning resources area, students 
in the TLM rated it higher than students in the FCM, even though the resources and course materials were the same for both sections. In particular, participants in the FCM had lower ratings on questions such as "It was made clear what resources were available to help me learn" and "The study materials were clear and concise". One potential explanation could be the class level of the participants. The majority of students in the FCM were juniors (73\%), compared to the TLM, which had a much more even distribution of juniors and seniors $(46 \%$ and $48 \%$, respectively). It is possible that by the time students reach senior status, they had more exposure to online classes and were better equipped to orient themselves in finding the learning resources.

Taking a closer look at course organization, it appeared that the differences between the groups were driven by systematic organization of course content, sufficient flexibility in the course, and student choice of topic to study. The fact that the FCM participants had lower ratings was interesting, because all course content was available when the semester started and participants in both groups were allowed to have the same input into the learning material. For example, in the second module on reviewing literature, students in both groups were allowed to choose a study instead of the instructor choosing for them. The flexibility issue is also of particular interest since our findings seem to contradict previous studies that support the selfpaced character of the FCM as a benefit to students (Davies et al., 2013; Lujan \& DiCarlo, 2014). This would suggest that students were more comfortable with the traditional learning environment, which is in agreement with conclusions drawn by Roehl, Reddy, and Shannon (2013) in that it may require more than a semester to adapt to the new method of instruction and to recognize its value.

With regards to basic needs satisfaction, two of the subscales were not reliable and were therefore not analyzed. The remaining basic need, relatedness (an experience of warmth, care, concern, and support vis-à-vis important others; Niemiec \& Ryan, 2009), did not differ significantly between groups. However, it is encouraging to note that perceptions of relatedness were high in both groups. This would indicate that students felt connected to their instructor throughout the course independent of the model: TLM or FCM. Relatedness is one of the basic psychological needs at the core of SDT and provision of such a need is associated with an improved learning environment. This seems to support previous findings that indicated that the FCM provide improved learning environments (Baepler et al., 2014).

Although there was no significant difference between academic motivations in TLM and FCM, the findings indicated high values for extrinsic motivation in both groups supporting previous studies that indicated students' preference for extrinsic motivation (Maurer et al., 2012, 2013). For example, the TLM students reported highest scores on two least autonomous types of motivation - external regulation and introjected regulation. This indicates that students tend to be driven by external rewards or the avoidance of punishment. The FCM students reported highest values on external regulation and ranked introjected regulation third. It is encouraging that intrinsic motivation to know was high among both groups, ranking second in the FCM and third in the TLM, indicating that some students do enjoy learning new things just for the pleasure of learning research methods. In the educational context, provision of relatedness (along with autonomy and competence) stimulates more autonomous types of motivation, which improve academic outcomes. In this respect, our findings are crucial in supporting that the FCM performed just as well as the TLM. It is possible that this also contributed to high scores and high rankings on intrinsic motivation to know.

The third purpose of this study was to investigate possible differences in academic performance, as measured by final course grade percentages. No differences in average grade 
percentage in the course were seen between groups, and much like relatedness, grades were favorable for progression in the major. Our findings support some previous studies (Davies et al., 2013; Johnson \& Renner, 2012; Lage et al., 2000; 35), but contradict other studies (Chen, Wang, \& Chen, 2014; Tune et al., 2013) adding to the inconsistent results in the literature. Due to the direct comparison between two groups with the same instructor, materials and assessments, it seems to suggest that the FCM is at least as good as the TCM and is not detrimental to student learning. In other words, for those instructors that prefer a more indirect and active learning approach, the FCM might be a viable alternative.

Lecture viewing is a vital component of the FCM. Although there is no universal script for flipped classrooms, pre-class preparation is crucial to students because it allows them to focus on solving problems in class and being an active participant. As such, investigating viewing patterns was an important feature of this study. Overall, lecture-viewing time in the FCM decreased significantly during the semester. In fact, there was a clear difference between viewing times before and after the midterm. This is not independent from the results gathered concerning course experience and tends to support some other findings indicating students' lack of preparation time prior to class (Bristol, 2014). However, they contradict findings by DeGrazia et al. (2012) who reported that students tended to watch the videos when assigned. This finding is also particularly interesting considering that students in the FCM reported lower scores with availability of resources. It would appear, based on the data for the current study, that students did not utilize the resources they were given, again contradicting DeGrazia et al. (2012), who reported that even when students did not watch the videos, those who were provided with optional video lectures came to class much better prepared than when they were given textbook readings. Our study did not examine reading compliance in the TLM, but the data suggests that the students who watched a greater percentage of each lecture earned a higher grade than those who watched very little. It is recommended to share this data with students in an attempt to promote better adherence to lecture viewing.

Although not a direct goal of the study, our data demonstrated the reliability for the AMS adapted specifically for research methods classes as reported in the literature (Maurer et al., 2012). As such, other instructors of research methods can use it to study academic motivation.

\section{Limitations}

This study is not without its limitations. One limitation is the fact that classes were not randomized. Students enrolled in different sections of the course based on convenience or schedule of other classes needed for their major. This resulted in slight demographic differences, which may play a role in explaining the results of the study. However, this is normal academic practice and this limitation is unavoidable. In addition, two of the subscales from the basic need satisfaction questionnaire were unreliable in this sample. Without that information, it is not possible to draw conclusions about students' perceptions of autonomy and competence. Another limitation was the fact that the FCM was applied by only one instructor to one type of class. Since two sections were offered each semester, it is possible that participants in one section discussed the course with participants in the other sections. This was unavoidable as the study occurred in an actual classroom environment.

\section{Future Research}

Based on these limitations, several recommendations for future research include continued validation of scales to evaluate basic need satisfaction in this population. As a basic feature of 
self-determination theory, the connection between basic needs, motivation, and academic performance still needs to be addressed. Results from this study indicate that students in the FCM did not adhere to lecture viewing, although they did report preparing for class by reading. Future research should investigate teaching methods that can increase adherence to lecture viewing, as it is an integral part of the FCM experience. Although the data collected is rich in information, future work from a qualitative perspective may help to uncover some of the experiences of students in the FCM.

\section{Conclusions}

In conclusion, results from this study indicate that the FCM could be a viable alternative to the TLM format in undergraduate courses. Along with having similar levels of satisfaction with course experience, motivation, and grades, attendance was higher in the FCM. Depending on the goals of the instructor, this method shows promise for educating health science undergraduates in a format that is more interactive and may engage students within the field in better ways.

\section{References}

Baepler, P., Walker, J. D., \& Driessen, M. (2014). It's not about seat time: blending, flipping, and efficiency in active learning classrooms. Computers \& Education, 78, 227-236. https://doi.org/10.1016/j.compedu.2014.06.006

Barnett, R. (2004). The purposes of higher education and the changing face of academia. London Review of Education, 2(1), 61-73. https://doi.org/10.1080/1474846042000177483

Bergmann, J., \& Sams, A. (2012). Flip your classroom: reach every student in every class every day. International Society for Technology in Education.

Bishop, J. L., \& Verleger, M. A. (2013, June). The flipped classroom: a survey of the research. In ASEE National Conference Proceedings, Atlanta, GA (Vol. 30, No. 9).

Block, B. A., \& Estes, S. (2011). Supercomplexity in Higher Education Kinesiology. Quest, 63(2), 179-196. https://doi.org/10.1080/00336297.2011.10483675

Bristol, T. (2014). Flipping the classroom. Teaching and Learning in Nursing,9(1), 43-46. https://doi.org/10.1016/j.teln.2013.11.002

Brunsell, E., \& Horejsi, M. (2013). Flipping your classroom in one" take". The Science Teacher, 80(3), 8.

Chen, Y., Wang, Y., \& Chen, N. S. (2014). Is FLIP enough? Or should we use the FLIPPED model instead? Computers \& Education, 79, 16-27. https://doi.org/10.1016/j.compedu.2014.07.004

Day, J. A., \& Foley, J. D. (2006). Evaluating a web lecture intervention in a human-computer interaction course. IEEE Transactions on Education, 49(4), 420-431. http://doi.org/10.1109/TE.2006.879792

Davies, R. S., Dean, D. L., \& Ball, N. (2013). Flipping the classroom and instructional technology integration in a college-level information systems spreadsheet course. Educational Technology Research and Development,61(4), 563-580. http://doi.org/10.1007/s11423-013-9305-6

De Grazia, J. L., Falconer, J. L., Nicodemus, G., \& Medlin, W. (2012). Incorporating screencasts into chemical engineering courses. In American Society for Engineering Education. American Society for Engineering Education.

Journal of the Scholarship of Teaching and Learning, Vol. 18, No. 4, December 2018.

josotl.indiana.edu 
Deci, E. L., \& Ryan, R. M. (2000). The" what" and" why" of goal pursuits: Human needs and the self-determination of behavior. Psychological Inquiry, 11(4), 227-268. http://doi.org/10.1207/S15327965PLI1104_01

Fitzgerald, N., \& Li, L. (2015). Using presentation software to flip an undergraduate analytical chemistry course. Journal of Chemical Education,92(9), 1559-1563. http://doi.org/10.1021/ed500667c

Frederickson, N., Reed, P., \& Clifford, V. (2005). Evaluating web-supported learning versus lecture-based teaching: Quantitative and qualitative perspectives. Higher Education, 50(4), 645-664. http://doi.org/10.1007/s10734-004-6370-0

Gerstein, J. (2012, May). Flipped classroom: the full picture for higher education. User Generated Education. Retrieved from https://usergeneratededucation.wordpress.com/2012/05/15/flipped-classroom-the-fullpicture-for-higher-education/

Griffin, P., Coates, H., Mcinnis, C., \& James, R. (2003). The development of an extended course experience questionnaire. Quality in Higher Education,9(3), 259-266. http://doi.org/10.1080/135383203200015111

Goodwin, B., \& Miller, K. (2013). Evidence on flipped classrooms is still coming in. Educational Leadership, 70(6), 78-80.

Johnson, L. W. \& Renner J.D. (2012). Effect of the flipped classroom model on a secondary computer applications course: Student and teacher perceptions, questions and student achievement (Doctoral dissertation, University of Louisville).

Kim, M. K., Kim, S. M., Khera, O., \& Getman, J. (2014). The experience of three flipped classrooms in an urban university: An exploration of design principles. The Internet and Higher Education, 22, 37-50. http://doi.org/10.1016/j.iheduc.2014.04.003

Lage, M. J., Platt, G. J., \& Treglia, M. (2000). Inverting the classroom: A gateway to creating an inclusive learning environment. The Journal of Economic Education,31(1), 30-43. http://doi.org/10.1080/00220480009596759

La Guardia, J. G., Ryan, R. M., Couchman, C. E., \& Deci, E. L. (2000). Within-person variation in security of attachment: A self-determination theory perspective on attachment, need fulfillment, and well-being. Journal of Personality and Social Psychology, 79(3), 367384. http://doi.org/10.1037/0022-3514.79.3.367

Lemmer, C. A. (2013). View from the flip side: using the inverted classroom to enhance the legal information literacy of the international LL. M. student. Law Library Journal, 105, 461.

Lujan, H. L., \& DiCarlo, S. E. (2014). The flipped exam: creating an environment in which students discover for themselves the concepts and principles we want them to learn. Advances in Physiology $\quad$ Education, 38(4), 339-342. http://doi.org/10.1152/advan.00081.2014

Lumpkin, A., Achen, R., \& Dodd, R. (2015). Focusing teaching on students: Examining student perceptions of learning strategies. Quest, 67(4), 352-366. http://doi.org/10.1080/00336297.2015.1082143

Machemer, P. L., \& Crawford, P. (2007). Student perceptions of active learning in a large crossdisciplinary classroom. Active Learning in Higher Education, 8(1), 9-30. http://doi.org/10.1177/1469787407074008

Maurer, T., Allen, D., Gatch, D. B., Shankar, P., \& Sturges, D. (2012). Students' academic motivations in allied health classes. Internet Journal of Allied Health Sciences and Practice, 10(1), 6. 
Maurer, T. W., Allen, D., Gatch, D. B., Shankar, P., \& Sturges, D. (2013). Students' academic motivations in three disciplines. Journal of the Scholarship of Teaching and Learning, 13(5), 77-89.

McLaughlin, J. E., Roth, M. T., Glatt, D. M., Gharkholonarehe, N., Davidson, C. A., Griffin, L. M., \& Mumper, R. J. (2014). The flipped classroom: a course redesign to foster learning and engagement in a health professions school. Academic Medicine, 89(2), 236-243. http://doi.org/10.1097/ACM.0000000000000086

Miller, C. J., McNear, J., \& Metz, M. J. (2013). A comparison of traditional and engaging lecture methods in a large, professional-level course. Advances in Physiology Education, 37(4), 347-355. http://doi.org/10.1152/advan.00050.2013

Missildine, K., Fountain, R., Summers, L., \& Gosselin, K. (2013). Flipping the classroom to improve student performance and satisfaction. Journal of Nursing Education, 52(10), 597-599. http://doi.org/10.3928/01484834-20130919-03

Moravec, M., Williams, A., Aguilar-Roca, N., \& O'Dowd, D. K. (2010). Learn before lecture: A strategy that improves learning outcomes in a large introductory biology class. CBE-Life Sciences Education, 9(4), 473-481. http://doi.org/10.1187/cbe.10-04-0063

Niemiec, C. P., \& Ryan, R. M. (2009). Autonomy, competence, and relatedness in the classroom: Applying self-determination theory to educational practice. Theory and Research in Education, 7(2), 133-144. http://doi.org/10.1177/1477878509104318

Roehl, A., Reddy, S. L., \& Shannon, G. J. (2013). The flipped classroom: An opportunity to engage millennial students through active learning. Journal of Family and Consumer Sciences, 105(2), 44-49. http://doi.org/10.14307/JFCS105.2.12

Ryan, R. M., \& Deci, E. L. (2000). Self-determination theory and the facilitation of intrinsic motivation, social development, and well-being. American Psychologist, 55(1), 68-78. http://doi.org/10.1037/0003-066X.55.1.68

Strayer, J. F. (2007). The effects of the classroom flip on the learning environment: $A$ comparison of learning activity in a traditional classroom and a flip classroom that used an intelligent tutoring system (Doctoral dissertation, The Ohio State University).

Tucker, B. (2012). The flipped classroom. Education Next, 12(1), 82-83.

Tune, J. D., Sturek, M., \& Basile, D. P. (2013). Flipped classroom model improves graduate student performance in cardiovascular, respiratory, and renal physiology. Advances in Physiology Education, 37(4), 316-320. http://doi.org/10.1152/advan.00091.2013

Vallerand, R. J., Pelletier, L. G., Blais, M. R., Briere, N. M., Senecal, C., \& Vallieres, E. F. (1992). The academic motivation scale: a measure of intrinsic, extrinsic, and amotivation in education. Educational and Psychological Measurement, 52(4), 1003-1017. http://doi.org/10.1177/0013164492052004025

Westermann, E. B. (2014). A half-flipped classroom or an alternative approach?: Primary sources and blended learning. Educational Research Quarterly, 38(2), 43-57.

Wilson, S. G. (2013). The flipped class: A method to address the challenges of an undergraduate statistics course. Teaching of Psychology, 40(3), 193-199. http://doi.org/10.1177/0098628313487461

Zappe, S., Leicht, R., Messner, J., Litzinger, T., \& Lee, H. W. (2009). Flipping the classroom to explore active learning in a large undergraduate course. In American Society for Engineering Education Annual Conference \& Exhibition. American Society for Engineering Education. 